\title{
BMJ Open How does the public conceptualise the quality of care and its measurement in community pharmacies in the UK: a qualitative interview study
}

Margaret C Watson, ${ }^{\oplus 1}$ Karin Silver, ${ }^{1}$ Ross Watkins ${ }^{\odot 2}$

To cite: Watson MC, Silver K, Watkins R. How does the public conceptualise the quality of care and its measurement in community pharmacies in the UK: a qualitative interview study. BMJ Open 2019;9:e027198. doi:10.1136/ bmjopen-2018-027198

- Prepublication history for this paper is available online. To view these files, please visit the journal online (http://dx.doi. org/10.1136/bmjopen-2018027198).

Received 12 0ctober 2018 Revised 12 February 2019 Accepted 13 February 2019

A) Check for updates

(c) Author(s) (or their employer(s)) 2019. Re-use permitted under CC BY-NC. No commercial re-use. See rights and permissions. Published by BMJ.

${ }^{1}$ Department of Pharmacy and Pharmacology, University of Bath, Bath, Somerset, UK

${ }^{2}$ Population Health Sciences, University of Bristol Medical School, Bristol, UK

Correspondence to Professor Margaret C Watson; m.c.watson@bath.ac.uk

\section{ABSTRACT}

Objectives This study explored citizens' perspectives about the quality of community pharmacy services in the UK and whether and how the quality of community pharmacy services should be measured.

Design Semistructured interviews and focus groups were conducted and were audio recorded, transcribed and analysed systematically using an interpretive approach.

Participants Members of the public were approached via networks, such as Health and Social Care Alliance Scotland, as well as community groups and personal networks.

Setting Scotland, England and Wales.

Results Data were collected from 20 participants:

11 interviews and 2 focus groups (in community settings, with five and four participants). Quality was conceptualised as multidimensional with interrelated overarching themes of person-centredness, professionalism and privacy. The importance of relational aspects with pharmacy personnel was emphasised including the need for a 'friendly' caring service, continuity of care, being known to personnel, including their awareness of individual's health conditions: 'it's quite a personal service I would say...I think it means that they care about your welfare'. Participants discussed the importance of a professional approach to customer interactions including staff behaviour and appearance. Pharmacy design influenced perceptions of privacy, including having sufficient space or a separate consultation room to promote confidential consultations with a pharmacist. Participants suggested that quality assurance is needed to improve quality and to inspire confidence in the public 'it would drive up quality standards overall' but suggested that quality ratings were unlikely to influence their use of specific pharmacies. They emphasised the need for multidimensional quality ratings and for transparency with their derivation.

Conclusions The public conceptualises quality of community pharmacy services as multidimensional and value relational aspects of care provided by personnel in this setting. While the development and application of quality indicators may drive improvement, it seems unlikely to influence the public's use of individual pharmacies.
Strengths and limitations of this study

- A diverse range of individuals participated in terms of age, sex and country but not ethnicity.

- Data collection was undertaken by one experienced health service researcher who was also a pharmacist

- Data analysis was undertaken by two experienced qualitative researchers neither of whom were pharmacists. This ensured a balanced approach to the analysis and interpretation of the data.

All key recurring themes were identified with no new themes emerging in later interviews or focus groups.

\section{INTRODUCTION}

Each year in the UK, an estimated 650000 emergency department consultations and 18 million general practitioner consultations are for conditions (hereafter referred to as self-care consultations) that can be treated effectively by community pharmacy personnel, equating to around $£ 1.1$ billion in resources. ${ }^{1-2}$ In England, each of the 11699 community pharmacies ${ }^{3}$ serves an average population of around 5600 citizens $^{4}$ of whom an estimated $89 \%$ are within a 20 minute walk of a community pharmacy. ${ }^{5}$ National policies and resources recommend the public to seek care from the most 'appropriate' provider. $^{6-8}$ Reassurance is needed regarding the quality of care provided in community pharmacies in general, and more specifically for self-care, which has been shown to vary, depending on the criteria used. ${ }^{9-11}$ While national quality indicators for community pharmacy were introduced in England in $2017^{12}$, none refer to the management of self-care consultations despite this service being regarded the 'shop window' of community pharmacy. ${ }^{13}$ As such, the study presented here is part of a research programme to coproduce quality indicators for self-care consultations. 
The aim of this study was to conceptualise public perceptions and beliefs about the:

- Quality of community pharmacy services in general.

- Management of self-care consultations.

- Measurement of the quality of community pharmacy services.

\section{METHODS}

\section{Study design}

Interviews and focus groups were conducted with members of the public with the method used varying according to participant availability and preference.

\section{Recruitment, sampling and consent}

Participants were recruited through existing networks such as Health and Social Care Alliance Scotland, ${ }^{14}$ as well as community groups and personal networks. Individuals were eligible to participate if they used community pharmacy services, and understood and were able to communicate in English. An email was sent to potential participants with information about the study, advising them to contact the research team if they wished to participate. Recruitment ceased once theoretical saturation was reached (ie, when no new themes were emerging from the data). A maximum variation sample was recruited using a combination of purposive, convenience and snowballing techniques. ${ }^{15}$

\section{Data collection}

One female researcher (MW), who is a registered pharmacist with 25 years' experience of health services research, undertook all data collection. Audio-recorded face-toface or telephone interviews were conducted between August 2016 and July 2017, and lasted an average of 51 minutes (range $31-74$ minutes). No other individuals were present during the interviews or focus groups. The topic (interview) guide was informed by existing work on quality and quality improvement, as well as a precedent interview study involving pharmacists. ${ }^{13}$ It was not piloted prior to use but was modified throughout the data collection process to incorporate relevant topics identified in earlier interviews and focus groups. This is consistent with an inductive approach in which theory emerges iteratively and develops through the analysis of data. The concepts of 'what matters to you', 'always events' and 'never events' were included. ${ }^{13}{ }^{16}$ Always events are 'aspects of the patient experience that are so important to patients and families that healthcare providers must aim to perform them consistently and reliably for every patient, every time'. ${ }^{17}$

Quality measurement was explored in general terms and more specifically in relation to the use of rating or accreditation systems. The same topic guide was used for interviews and focus groups. As new issues or themes emerged, they were included in subsequent interviews/ focus groups. On completion of the interviews/focus groups, participants were offered a 'thank you' voucher worth $£ 20$.

\section{Data analysis}

Audio recordings were transcribed verbatim by an experienced transcriber and accuracy checked (KS/RW). The data were analysed systematically using thematic analysis. ${ }^{18-19}$ The focus of the analysis was to organise the data in a meaningful way according to the a priori aims of the study, as well as to allow for the identification of topics and issues of importance to participants. NVivo V.11 (QSR International) was used to help organise, code and explore the data. Two researchers (KS, RW) first familiarised themselves with the transcripts and coded to broad topic areas (structuring codes). The next (extensive and iterative) phase involved the identification of themes and subthemes to reflect the research questions (a priori codes/nodes) and from within the data itself (in vivo codes/nodes). As the analysis progressed, conceptual and cross-cutting themes were identified and coded, in addition to relevant topic codes.

Each transcript was coded by one researcher (KS or $\mathrm{RW})$, with most coded by two researchers (KS, RW) to ensure reliability. The themes, their names and explanations were continually refined through discussion between the researchers to ensure that they were distinct from other themes, internally coherent and consistently applied. The coded data were explored through queries and other NVivo tools, and themes were mapped to identify connections. Once coding was complete, a framework approach ${ }^{20}$ was used to support the systematic analysis of data around the research questions, to enable an assessment of prevalence and coverage of key themes (ie, dimensions of quality). Further interpretation and discussion, to ensure that analytical claims were congruent with the extracts, culminated in the creation of a thematic resource document. This reported all the relevant coded data under overarching themes/headings, with some extracts being duplicated under two or more themes (eg, in the case of richness or complexity). This study is reported in accordance with Consolidated criteria for Reporting Qualitative research ${ }^{21}$.

\section{Patient and public involvement statement}

We did not involve patient and public involvement (PPI) representatives in the development of the research questions and outcome measures or in the design of the study. However, patients and the public were recruited through: the Scottish Patient Alliance; two participants in England were recruited through PPI groups; and the English and Welsh focus group participants were recruited through professional contacts of the researchers. Study results will be disseminated to all participants who expressed an interest in being informed of the results using a plain language summary that will be sent via email or in the post. All participants were thanked in the acknowledgements.

\section{RESULTS}

In total, 20 individuals participated (Scotland $(n=7)$ all interviewed individually; England (one focus group $(n=4)$ 
Table 1 Participant characteristics

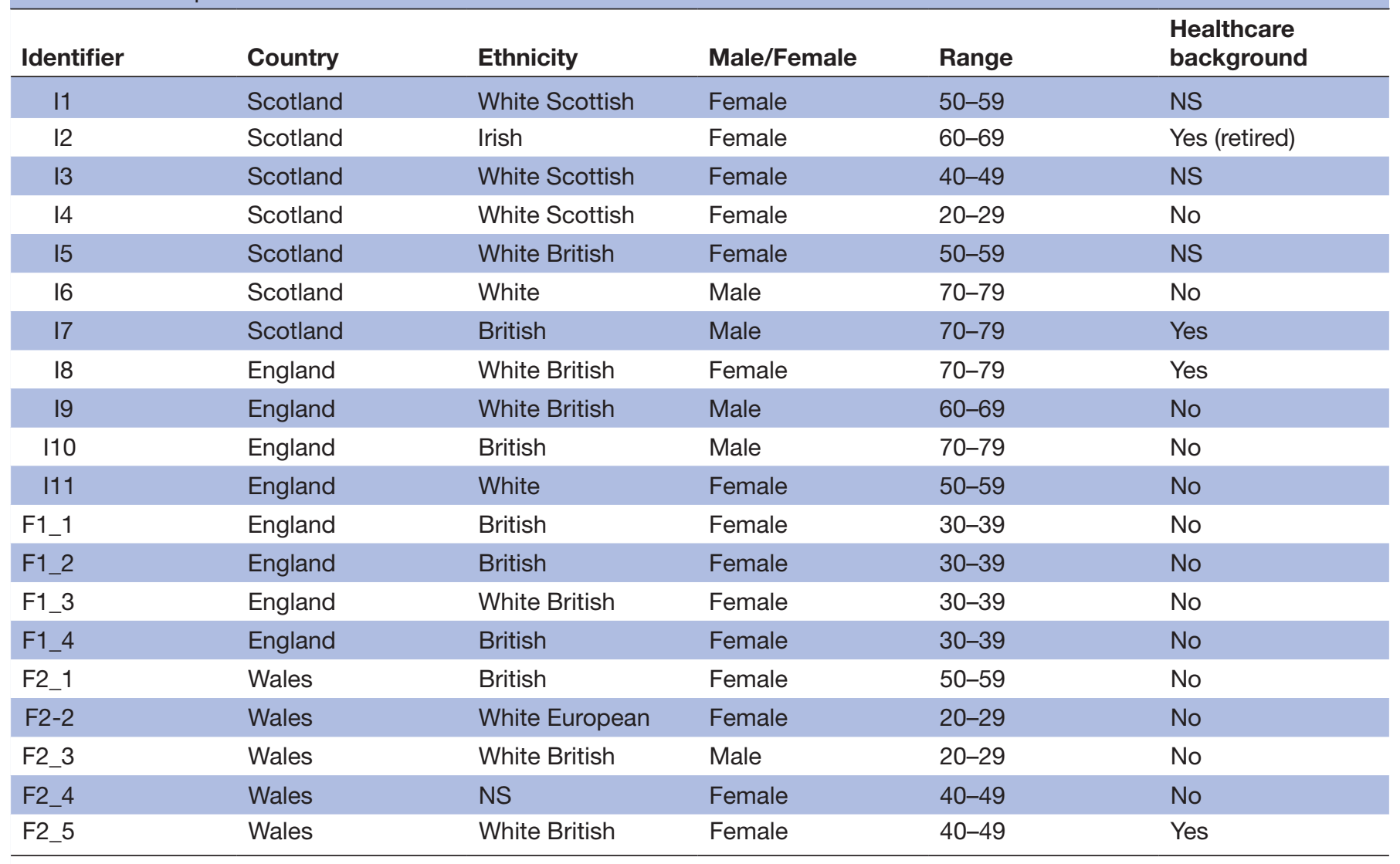

I, interview; F, focus group; NS, not stated.

and four individual interviews (one of which was face to face)); and Wales (one focus group $(\mathrm{n}=5)$ ) (table 1). The majority were British and female. Four participants had been employed previously in health-related employment (none reported pharmacy-related employment although one male sometimes worked as a delivery driver for a local pharmacy). The focus group in England comprised four women in their 30s, all parents of young children. The focus group in Wales comprised three women in their 40s and 50s who were all mothers, and two graduate students in their 20s. All seven participants in Scotland were recruited through the Scottish Patient Alliance, two participants in England were recruited through PPI groups, and the English and Welsh focus group participants were recruited through professional contacts of the researchers (MW, RW).

\section{Dimensions of quality: the three P's}

When asked 'what matters to you', participants conceptualised the quality of community pharmacies as multidimensional and inter-related with three overarching themes: person-centredness, professionalism and privacy. Selected quotes are presented to illustrate these dimensions and themes (Identifiers I and F denote interview and focus group participants, respectively).

\section{Person-centredness}

Participants emphasised the importance of relational aspects with pharmacy personnel including the need for a 'friendly' caring service, continuity of care and the staff 'knowing' the individual, including awareness of their health conditions.

I4: The staff are really friendly, and helpful,... it's quite a personal service I would say...I think it means that they care about your welfare.

I8: I like continuity... It makes me feel safer, and um...it's like your doctor, you want your doctor to know you... it's nice to think that this person knows you and might actually take an interest in you as opposed to you're just the next customer.

They generally wanted easy access to a pharmacist and pharmacies in terms of geographical proximity and location, as well as opening hours, which suited their needs and lifestyle, and suitable parking or access by public transport. However, others were willing to travel further for specific medication needs or a better service.

Some also wanted the pharmacist to be visible and accessible in the pharmacy.

I9:...direct access, easy access to the pharmacist (...) because there are some pharmacists [sic] you go to 
where the registered pharmacists is like someone hiding behind... a curtain and you don't see them.

F1_1: They [counter staff] are the gatekeepers aren't they?. .the pharmacist is in the back, somewhere you know? It does feel like you have to have something really legitimate to speak to them rather than them being available to speak to you (...). I don't know the rules. I would like to know the answer to that - when am I entitled to speak to the pharmacist?

Interviewees felt that staff should take time to listen and communicate clearly, involve people in decisions around their own treatment, be responsive to personal requirements and preferences and be respectful of individual concerns.

I10: [there should always be] a feeling that the person you are talking to has time for you obviously. If you have the feeling that you are being a nuisance then you would be reluctant to ask a second time.

\section{Professionalism}

Participants discussed the importance of a professional approach in customer interactions including staff behaviour and appearance. Although not all expected staff to wear a uniform, it was commonly felt that they should be identifiable, for example, by wearing name badges.

I11: The staff would look clean and smart and presentable and the name badge confirming that they are not just Saturday girls, they are kind of trained professionals.

F1_2: I guess maybe for them to tell you who they are-introduce themselves. 'I am a pharmacist' orso that you know exactly who you're dealing with.

People expected staff (including, but not only, pharmacists) to be competent, suitably trained, qualified and confident in their ability to diagnose, advise and prescribe, and for all staff to be knowledgeable about over-the-counter medication (ie, medicines, which can be sold/bought without the need for a prescription), and be able to provide (cheaper) alternatives.

F2_3: If they are still uncertain they should always refer you back to your GP

F1_3: I don't know if it was the pharmacist or the pharmacy assistant to be honest but she basically advised me to take a slightly cheaper model of the medicine... . . And I really appreciated it, that's a nice thing to do.

Counter staff were expected to defer to the pharmacist if necessary, who should then refer onward as appropriate, but not be overly risk averse (a frustration for parents of young children).

F1_2: [I] went a few times when [name of child] was younger and then because I just kept getting...'I don't know what's wrong with him, he's got like a bit of a rash, or something, is there anything you can give me?' and they were like 'oh we wouldn't like to say just go and see the GP'. Now... I will go straight to the GP. .because...they don't ever seem keen to actually sort of [sic] not diagnose.

Participants felt it was important that a pharmacy felt clean, light and 'hygienic'. It was felt that a good quality pharmacy should have sufficient medication stock so that prescriptions could be fully filled, in a timely manner, to avoid return visits.

I6: It's got to be how quickly you receive whatever medicine or treatment you need... that's the most important thing.

\section{Privacy}

Privacy was an important consideration and included physical characteristics of the pharmacy in supporting privacy, with either a separate consultation room or a dedicated private area, and the need to have confidential conversations with the pharmacist.

I2: Private consultation room that's accessible. Not at the back of the shop (...) I don't think there should be over the counter consultations at the same section where people are coming to buy their cosmetics or whatever or pick up their prescriptions...it should be separate, in fact go into [ supermarket pharmacy] you've got to queue up with everybody that's wanting their fags, or wants a lottery ticket.

Privacy was interwoven with confidentiality, which in turn, influenced confidence and trust in pharmacy personnel.

I11:...they reassure you...( ()...you that it is a private consultation maybe and that your data is protected as a minimum I suppose.

I5: We do have a village pharmacy, but because of the lack of confidentiality I am now taking myself a 52 mile round trip to get a prescription...() It matters that I feel confident in the service that I'm being given, that I'm confident in the fact that my information is being kept confidential, and that the fact is that the pharmacists on the whole genuinely are trying to do their best by patients.

\section{Measuring quality in community pharmacies}

Participants were asked whether the quality of community pharmacies should be measured and if so, what measures to use. Participants suggested that quality assurance is needed to improve quality as well as to inspire confidence in the public.

I5:. the only way you're going to know that you're going to get a good service is to actually publish the fact that you are getting a good service. It's like in hospital wards for cleanliness, now they're putting up figures showing that they've managed to eliminate for the 
last 100 days-they've had no MRSA-that gives confidence to patients when they read that and see these facts and figures. And they're put out there for everybody to see not just the few, that's important.(...). it would be about saying to the good pharmacists 'well done you're getting it right every time'. But it's also saying to the other ones 'you need to pull your socks up'.

There was recognition that quality could be difficult to measure across varied services and discussion of which criteria to use.

F2_4: How effective was the information or how accurate was the information you received, did it work for you, was it right or was it wrong or, how satisfied were you on what you were told, and I think that's it in a nutshell really. (...)

Suggested methods of quality measurement included: customer satisfaction surveys/instant feedback; audit; mystery shoppers and the use of professional standards. The use of rating systems was explored specifically. Participants identified similar systems associated with other aspects of life, including: shopping (Amazon); travel (Trip Advisor); restaurants (food hygiene ratings); health (hospital wards) and education services (Ofsted (Office for Standards in Education)). Many participants expressed broadly positive attitudes towards rating systems, while others questioned their usefulness based on the use of similar systems applied to other areas, for example, education. The relevance of these systems to community pharmacies was also questioned due to the more complex, less 'transactional' element of service/ customer interaction.

I9: There are ratings systems for things that-where a service can damage the public...(). we already have food safety ratings for cafes and restaurants. One might ask why we don't have one for something where the service could kill you more effectively, or more easily.(). you can tell a reasonable restaurant or cafe from your first consumer experience, you won't necessarily know a really good pharmacy from a less than good pharmacy.

Participants described potential positive, negative and unintended consequences of a star-type rating system for reporting quality.

I4: I think it would drive up quality standards overall. Yeah, I think it would be a good measure. If chemists know that they're being rated they obviously wouldn't want a bad rating.

I8:. . I realise how frightened people are of their health...so I think if they went into a chemist shop and saw that maybe it only had 3 and room for improvement, I think they'd [the public] get nervous about that. So yes, there can be a rating but I don't think it really needs to be displayed when it comes to health.

Some participants considered rating systems to be too subjective.

F2_1: . if it was general public rating then I'd be a bit sceptical but if it came from a professional going in and give it an accredited, like the scores on the door, like it comes from a governing body ... then I would have more tendency to go with what they said, . . a non-biased organisation. . and you were judged (...) Maybe give it different categories, maybe the customer service side ask the general public, but as far as the professional-the accuracy of what was given out and the way everything was kept-leave that part to the professionals because I wouldn't be anyone to judge.

Most participants stated that they would take notice of star ratings if they existed, but would not necessarily base their choice of pharmacy on them. Some preferred to make their own judgement. For most, the decision to use a particular pharmacy was contingent on a number of potentially overlapping factors including accessibility, personal needs, time available and perceived urgency. Given that most also expressed general satisfaction with the pharmacy they used, and some had no realistic choice of using another, there was some scepticism around the value of a star ratings type system in terms of what it might be based on and how it would be used.

F2_2: It wouldn't affect my choice of the pharmacy unless it was maybe a one star out of five then I'd be like well 'what's going on here like why' but if it was four or three I'd probably wouldn't care because I probably wouldn't understand what the rating is based on, who gave this rating to this particular pharmacy. I mean in restaurants I know that if the hygiene-so I can imagine what it means-but in a pharmacy, but is it the customer service, is it the way they organise their medicines, I'd probably just base my choice—based on my experience.

\section{DISCUSSION}

\section{Statement of principal findings}

Quality was conceptualised as multidimensional with inter-related overarching themes of person-centredness, professionalism and privacy. The importance of relational aspects with pharmacy personnel was emphasised. Participants valued a professional approach including staff behaviour and appearance. Pharmacy design influenced perceptions of privacy, including having sufficient space or a separate consultation room to promote private and confidential consultations with a pharmacist.

Participants suggested that quality assurance would 'drive up quality standards overall' and inspire confidence in the public, but they intimated that quality ratings were unlikely to influence their use of specific pharmacies. 
They emphasised the need for multidimensional quality ratings and for transparency with their derivation.

\section{Strengths and weaknesses}

We included a diverse range of participants in terms of country, sex and age, but not ethnicity. We were satisfied that our sample size was appropriate in terms of answering our research questions relating to the conceptualisation of quality and its measurement. ${ }^{22}$ One experienced health service researcher, who was also a pharmacist (MW), undertook all data collection. She did not disclose her pharmacist background unless specifically asked. The breadth and depth of topics covered suggest that participants felt empowered to participate and share positive and negative experiences of community pharmacy use. Data analysis was undertaken by two experienced qualitative researchers (KS, female and RW, male) neither of whom were pharmacists. This ensured a balanced approach to the analysis and interpretation of the data. Our interpretive analysis explored participants' understanding and sense-making of their experiences of pharmacy services. We are confident that all key recurring themes were identified with no new themes emerging in the later interviews or focus groups.

\section{Important differences in the results}

None of the major themes derived from our study are reflected in the national quality indicators. This is perhaps unsurprising given that there was no PPI with indicator development. To date, there has been minimal PPI in the development of the few existing quality indicators for community pharmacy services. ${ }^{23-25}$ There has, however, been limited exploration of the likely influence of quality ratings on patient behaviour. Our participants anticipated that quality indicators would have little effect on their use of pharmacies, reflecting the results of two US studies that concurred that patients would only consider indicators if they were seeking a community pharmacy in a new area $^{26-27}$.

\section{Meaning of the study}

Our results show that the public value relational aspects of care, that is, personnel who are friendly and approachable, and reflect a recent UK-wide survey of over 1000 members of the public and their preferences for attributes of community pharmacies when seeking care for minor ailments (aka self-care consultations) ${ }^{28}$ As with these survey respondents, our participants also prioritised ease of access and convenience as important attributes.

\section{Implications for clinicians and policy-makers and unanswered questions and future research}

Future quality indicator development should involve stakeholders, particularly patients and public, as the main users of community pharmacy. Despite a possible lack of effect on care-seeking behaviour, the use of coproduced indicators could be used to drive quality improvement within and between community pharmacies.

\section{CONCLUSION}

The public conceptualises quality of community pharmacy services as multidimensional and they value relational aspects of care provided by personnel in this setting. While the development and application of quality indicators may drive improvement, it seems unlikely that they would influence the public's use of individual pharmacies.

Acknowledgements We thank all the members of the public who participated in interviews and focus groups as well as the organisations and individuals who facilitated recruitment of participants for this study.

Contributors MW led the scientific development and interpretation of the study, conducted most of the data collection and led manuscript production and revisions. KS advised on and developed analytical tools and frameworks, and contributed towards data analysis and interpretation, manuscript production and revisions. RW contributed towards data analysis and interpretation, manuscript production and revisions.

Funding This work was supported by the Health Foundation with MW's improvement science fellowship.

Competing interests None declared.

Patient consent for publication Not required.

Ethics approval The University of Aberdeen College Ethics Review Board provided ethical review and approval for the study (CERB/2015/6/1208).

Provenance and peer review Not commissioned; externally peer reviewed.

Data sharing statement № additional data are available. All data related to this study are included in this submission, either in tables in the manuscript or in online supplementary files

Open access This is an open access article distributed in accordance with the Creative Commons Attribution Non Commercial (CC BY-NC 4.0) license, which permits others to distribute, remix, adapt, build upon this work non-commercially, and license their derivative works on different terms, provided the original work is properly cited, appropriate credit is given, any changes made indicated, and the use is non-commercial. See: http://creativecommons.org/licenses/by-nc/4.0/.

\section{REFERENCES}

1. Fielding S, Porteous T, Ferguson J, et al. The burden of minor ailment consultations in general practice and emergency departments. Fam Pract 2015;32:165-72.

2. Watson MC, Ferguson J, Barton GR, et al. A comparison of health- and cost-related outcomes for patients presenting with similar symptoms in community pharmacies, general practices and emergency departments: A cohort study. BMJ Open 2015;5:e006261.

3. NHS Digital (National Statistics). General Pharmaceutical Services in England 2007/2008 to 2016/2017. https://digital.nhs.uk/data-andinformation/publications/statistical/general-pharmaceutical-services/ general-pharmaceutical-services-england-2007-08-to-2016-17\#keyfacts (Accessed 23/07/18).

4. Worldometer: UK Population (live). http://www.worldometers.info/ world-population/uk-population (Accessed 23 Jul 2018).

5. Todd A, Copeland A, Husband A, et al. The positive pharmacy care law: an area-level analysis of the relationship between community pharmacy distribution, urbanity and social deprivation in England. BMJ Open 2014;4:e005764.

6. NHS England. Transforming urgent and emergency care services in England. Urgent and emergency care review end of phase 1 report, 2013. Appendix 1-Revised evidence base from the urgent and emergency care review. The Urgent and Emergency Care Review. NHS, London.

7. NHS Choices: NHS services explained. https://www.nhs.uk/ NHSEngland/AboutNHSservices/Pages/NHSServices.aspx (Accessed 23 Jul 2018).

8. NHS Scotland: Know who to turn to. http://knowwhototurnto.org (Accessed 23 Jul 2018).

9. Pearl J. Are some pharmacies failing?. WHICH? 2013:26.

10. Studman A. Three in 10 pharmacies not following safety guidelines, finds Which? investigation. Which? 2018 https://www.which.co. 
uk/news/2018/02/three-in-10-pharmacies-not-following-safetyguidelines-finds-which-investigation (Accessed 23 Jul 18).

11. Inch J, Porteous T, Maskrey V, et al. It's not what you do it's the way that it's measured: quality assessment of minor ailment management in community pharmacies. Int J Pharm Pract 2017;25.

12. NHS England. Pharmacy quality payments: Quality criteria guidance. 2017 https://www.england.nhs.uk/wp-content/uploads/2017/02/ quality-payments-quality-criteria-guidance-1.pdf (Accessed $23 \mathrm{Jul}$ 2018).

13. Watson MC, Skea ZC. Jugglers and tightrope walkers: The challenge of delivering quality community pharmacy services. PLOS One 2018;13:e0200610.

14. Health and Social Care Alliance Scotland. https://www.alliancescotland.org.uk/ (Accessed 23 Jul 2018).

15. Bowling A. Research Methods in Health Care. Open University Press, Buckingham 2002.

16. Bowie P, McNab D, Ferguson J, et al. Quality improvement and person-centredness: a participatory mixed methods study to develop the 'always event' concept for primary care. BMJ Open 2015;5:e006667.

17. Institute for Healthcare Improvement. Always events toolkit. (Accessed 23 Jul 2018) http://www.ihi.org/resources/Pages/Tools/ Always-Events-Toolkit.aspx.

18. Attride-Stirling J. Thematic networks: an analytic tool for qualitative research. Qualitative Research 2001;1:385-405.

19. Braun V, Clarke V. Using thematic analysis in psychology. Qual Res Psychol 2006;3:77-101.
20. Ritchie J, Spencer L, O'Connor W. Carrying out qualitative analysis. Qualitative research practice: A guide for social science students and researchers, 2003.

21. Tong A, Sainsbury P, Craig J. Consolidated criteria for reporting qualitative research (COREQ): a 32-item checklist for interviews and focus groups. Int J Qual Health Care 2007;19:349-57.

22. Marshall MN. Sampling for qualitative research. Fam Pract 1996;13:522-6.

23. Halsall D, Noyce PR, Ashcroft DM. Characterizing healthcare quality in the community pharmacy setting: insights from a focus group study. Res Social Adm Pharm 2012;8:360-70.

24. Grey E, Harris M, Rodham K, et al. Characteristics of good quality pharmaceutical services common to community pharmacies and dispensing general practices. Int J Pharm Pract 2016;24:311-8.

25. Blalock SJ, Keller S, Nau D, et al. Development of the consumer assessment of pharmacy services survey. J Am Pharm Assoc 2012;52:324-32.

26. Shiyanbola OO, Mort JR. Patients' perceived value of pharmacy quality measures: a mixed-methods study. BMJ Open 2015;5:e006086

27. Warholak TL, Patel M, Rosenthal M, et al. Patient perceptions of a pharmacy star rating model. J Am Pharm Assoc 2017;57:311-7.

28. Porteous T, Ryan M, Bond C, et al. Managing minor ailments; the public's preferences for attributes of community pharmacies. A discrete choice experiment. PLoS One 2016;11:e0152257. 